\title{
Risk Factors of Secondary Lumbar Discectomy of a Herniated Lumbar Disc after Lumbar Discectomy
}

\author{
Joo Yul Beack, ${ }^{1}$ Hyoung Joon Chun, ${ }^{1}$ Koang Hum Bak, Kyu-Sun Choi, In-Suk Bae, ${ }^{1}$ Kee D. Kim ${ }^{2}$ \\ Department of Neurosurgery, Hanyang University Medical Center, Seoul, Korea \\ Department of Neurological Surgery, ${ }^{2}$ University of California, Davis, CA, USA
}

Objective : To study risk factors of secondary lumbar discectomy (LD) for recurrent herniated lumbar disc (HLD) and identify methods to lower the rate of recurrence.

Methods : Data from 160 patients who underwent primary LD were collected retrospectively. Demographic features, radiologic findings including Pfirrmann disc degeneration, and surgical information were analyzed to compare risks between revision and non-revision patients.

Results : The revision rate was $15 \%$ (24 patients), and the mean follow-up was 28.3 months. HLD recurrence was not related to any demographic characteristics. Primary and secondary LD were most common at the L4-5 level, but the level of operation was not significantly associated with revision. Primary LD most commonly had a Pfirrmann disc degeneration grade of 3 , followed by 4 . For recurrent HLD, Pfirrmann grade 4 was most common and was statistically significant $(p<0.05)$. A body mass index (BMI) over 30 was considered obese and was significantly related with HLD revision $(p<0.05)$.

Conclusion : Patients with high BMl or severe disc degeneration should be informed of HLD revision.

Key Words : Body mass index · Diskectomy · Recurrence · Reoperation.

\section{INTRODUCTION}

Lumbar discectomy (LD) is performed in patients with radicular pain caused by a herniated lumbar disc (HLD) after failed conservative treatments including medication, physiotherapy, and various neural blocks ${ }^{23}$. Considerable research has studied LD surgical techniques including open lumbar discectomy, microendoscopic discectomy, percutaneous endoscopic lumbar discectomy, and other modified techniques ${ }^{4}$.
Results of surgical LD are unsatisfactory in $3 \%$ to $19 \%$ of patients due to outcomes such as sustained pain, caudae eqinae, and recurrence. By radiologic imaging, recurrent HLD is found in $5 \%$ to $15 \%$ of these patients, and unresolved symptoms might lead to a secondary operation ${ }^{17,19,23)}$.

Risk factors of HLD recurrence including age, sex, body mass index (BMI), symptom duration, type of herniation, level of operation, degenerative changes, disc volume, and operative technique have been studied ${ }^{3,22,377}$.

- Received : April 4, 2019 •Revised : May 12, 2019 •Accepted : May 30, 2019

- Address for reprints : Hyoung Joon Chun

Department of Neurosurgery, Hanyang University Medical Center, 222 Wangsimni-ro, Seongdong-gu, Seoul 04763, Korea

Tel : +82-2-2290-8494, Fax : +82-2-2281-0954, E-mail : tdy815@hanayang.ac.kr, ORCID : https://orcid.org/0000-0001-9862-058X

This is an Open Access article distributed under the terms of the Creative Commons Attribution Non-Commercial License (http://creativecommons.org/licenses/by-nc/4.0) which permits unrestricted non-commercial use, distribution, and reproduction in any medium, provided the original work is properly cited. 
The purpose of this study was to investigate risk factors of secondary LD for recurrent HLD from a single surgeon's data.

\section{MATERIALS AND METHODS}

Owing to the retrospective nature of the study, this study was not approved by the Insitutional Review Board of Hanyang University Medical Center. Our study population in- cluded 160 patients who underwent open microscopic LD between 2009 and 2016 by a single surgeon in Hanyang University Medical Center.

Demographic information (age, sex, BMI, hypertension, diabetes mellitus, smoking, vertebral level of operation, and type of operation) and radiologic features (type of disc herniation, location of herniation, degree of disc degeneration, disc height, and height of vertebral body) were obtained retrospectively (Table 1). Postoperative magnetic resonance imaging

Table 1. Demographic features and surgical information

\begin{tabular}{|c|c|c|c|c|}
\hline & Total $(n=160)$ & Non-recurred $(n=136)$ & Recurred $(n=24)$ & $p$-value \\
\hline Age & $56.0(38.5-68.5)$ & $56.0(38.5-66.0)$ & $56.5(46.0-68.5)$ & 0.530 \\
\hline Sex & & & & 0.673 \\
\hline Male & $70(43.8)$ & $60(44.1)$ & $10(41.7)$ & \\
\hline Female & $90(56.2)$ & $76(55.9)$ & $14(58.3)$ & \\
\hline Hypertension & $51(31.9)$ & $45(33.1)$ & $6(25.0)$ & 0.585 \\
\hline Diabetes mellitus & $26(16.2)$ & $20(14.7)$ & $6(25.0)$ & 0.337 \\
\hline Smoking & $32(20.0)$ & $25(18.4)$ & $7(29.2)$ & 0.347 \\
\hline Body mass index & $27.2(24.7-32.8)$ & $26.9(24.7-29.5)$ & $29.8(27.1-32.8)$ & $0.011^{*}$ \\
\hline Disc type & & & & 0.270 \\
\hline Protrusion & $54(33.8)$ & $46(33.8)$ & $8(33.3)$ & \\
\hline Extrusion & $69(43.1)$ & $61(44.9)$ & $8(33.3)$ & \\
\hline Sequestration & $37(23.1)$ & $29(21.3)$ & $8(33.3)$ & \\
\hline Pfirrmann disc degeneration grade & & & & $0.001^{*}$ \\
\hline Grade 2 & $7(4.4)$ & $7(5.1)$ & $0(0.0)$ & \\
\hline Grade 3 & $92(57.5)$ & $85(62.5)$ & $7(29.2)$ & \\
\hline Grade 4 & $61(38.1)$ & $44(32.4)$ & $17(70.8)$ & \\
\hline Disc height & $9.4 \pm 2.0$ & $9.4 \pm 2.1$ & $9.5 \pm 1.7$ & 0.747 \\
\hline Body height & $23.0 \pm 2.2$ & $23.0 \pm 2.2$ & $23.3 \pm 2.2$ & 0.621 \\
\hline Disc/body height & $0.4 \pm 0.1$ & $0.4 \pm 0.1$ & $0.4 \pm 0.1$ & 0.921 \\
\hline Level of operation & & & & 0.183 \\
\hline L1-2 & $1(0.6)$ & $1(0.7)$ & $0(0.0)$ & \\
\hline L2-3 & $7(4.4)$ & $3(2.2)$ & $4(16.7)$ & \\
\hline L3-4 & $14(8.8)$ & $10(7.4)$ & $4(16.7)$ & \\
\hline$\lfloor 4-5$ & $85(53.1)$ & $75(55.1)$ & $10(41.7)$ & \\
\hline L5-S1 & $43(26.9)$ & $37(27.2)$ & $6(25.0)$ & \\
\hline Multilevel & $10(6.3)$ & $10(7.4)$ & $0(0.0)$ & \\
\hline Type of operation & & & & 0.542 \\
\hline Partial hemilaminectomy+lumbar discectomy & $98(61.2)$ & $83(61.0)$ & $15(62.5)$ & \\
\hline $\begin{array}{l}\text { Partial hemilaminectomy+foraminotomy+lumbar } \\
\text { discectomy }\end{array}$ & $62(38.8)$ & $53(39.0)$ & $9(37.5)$ & \\
\hline
\end{tabular}

Values are presented as mean \pm standard deviation, number (range), or number (\%). ${ }^{*} p$ value $<0.05$ is statistically significant by univariate logistic regression 
(MRI) was performed in patients with symptoms to confirm recurrence.

By assessing axial and sagittal MRI, herniation type was classified as protrusion, extrusion, or sequestration. Protrusion was a focal protrusion with an intact annulus fibrosus. Extrusion was a penetration of the nucleus pulposus (NP) through a defect in the annulus fibrosus. Sequestration was defined as a particle-free spinal canal.

The degree of disc degeneration was graded according to the Pfirrmann disc degeneration grade from using sagittal T2weighted MRI (Table 2). Disc height, vertebral body height and disc/vertebral body height ratio was estimated from the height of the disc and vertebral body in T2-weighted sagittal MRI. All patients were performed with discectomy and sequestration, and foraminotomy was performed in patients with foraminal stenosis on MRI finding. And the operation type was classified by degree of bone loss in the lamina and facet during primary surgery.

Statistical analysis was performed as follows. A logistic univariate regression was used to identify risk factors of HLD revision. Variables that were independent risk factors of secondary LD for recurrent HLD were analyzed by multivariate logistic regression, and the results were reported as an adjusted odds ratio (OR) and 95\% confidence interval (CI). A p-value $<0.05$ was considered to indicate a risk factor of HLD recurrence. All data were analyzed with $\mathrm{R}$ version 3.3.2 (R Foundation for Statistical Computing, Vienna, Austria).

Probability of revision surgery was assessed using the Kalpan-Meier method and log-rank tests.

Variables with a $p$-value $<0.10$ were re-entered in the multivariable logistic regression model using a backward stepwise method. To evaluate risk factors for revision, a multivariate logistic regression model with a backward stepwise method was used. ORs and 95\% CI were reported for statistically significant factors $(p$-value $<0.05)$. All data were analyzed with $\mathrm{R}$, version 3.3.2 (https://www.r-project.org/; R Foundation for Statistical Computing).

\section{RESULTS}

One hundred sixty patients underwent primary LD during the study period, and 24 patients underwent secondary LD. Patients with revision and non- revision HLD were of similar age (56.0 vs. 56.5 years). Also, sex did not differ between groups. In total, 51 patients had hypertension, 45 in the nonrecurrent group (33.1\%) and six in the revision group (25.0\%).

In the revision HLD group, the incidence of diabetes mellitus and smoking was more than 1.5 times higher than in the non- revision group, but the difference was not statistically significant $(p>0.05)$.

Herniated discs were classified as protrusion (54 patients), extrusion (69 patients), or sequestration (37 patients). In each group, eight patients underwent a second operation for revision HLD.

The highest revision rate (41.7\%) occurred at level L4-5 in 10 of 85 patients, followed by level L5-S1 in six of 43 patients (25.0\%). Four patients each had revision at level L2-3 or L3-4. Ten patients had a multi-level operation with no evidence of revision. Consequently, the level of operation was not statistically significant.

Demographic features and surgical information of our patients are listed in Table 1. Symptoms due to HLD recurrence were the only complication collected from our database.

A univariate analysis reported that Pfirrmann grade and BMI differed significantly between groups.

Table 2. Pfirrmann disc degeneration grade

\begin{tabular}{llcll}
\hline Grade & Structure & $\begin{array}{c}\text { Distinction of nucleus and } \\
\text { annulus fibrosus }\end{array}$ & Signal intensity & Intervertebral disc height \\
\hline 1 & Homogenous, bright white & Clear & $\begin{array}{c}\text { Hyperintense, isointense to } \\
\text { cerebrospinal fluid }\end{array}$ & Normal \\
\hline 2 & $\begin{array}{c}\text { Inhomogeneous with or without } \\
\text { horizontal bands }\end{array}$ & Clear & $\begin{array}{c}\text { Hyperintense, isointense to } \\
\text { cerebrospinal fluid }\end{array}$ & Normal \\
3 & Inhomogeneous, gray & Unclear & Intermediate & Normal to slightly decreased \\
\hline 5 & Inhomogeneous, gray to black & Lost & Intermediate to hypointense & Normal to moderately decreased \\
\hline 5 & Inhomogeneous, black & Lost & Hypointense & Collapsed \\
\hline
\end{tabular}


We estimated disc degeneration using Pfirrmann disc degeneration grade. Most patients were grade 3 (92 patients), followed by grade 4 ( 61 patients) and grade 2 (seven patients). No patients were grade 1 or 5 . In the revision HLD group, 17 patients $(70.8 \%)$ were grade 4 and the rest were grade 3 . Further analysis demonstrated that higher Pfirrmann grade was associated with an increased revision rate.

The association between BMI and HLD revision was also statistically significant $(p<0.05)$. The mean BMI of the revision HLD group was 29.8 (range, 27.1-32.8), and the mean BMI of the non-revision HLD group was 26.9 (range, 24.729.5). The total mean BMI was 27.2 (range, 24.7-32.8). We included overweight patients in the non-obese group. Obese patients were at 1.2-times higher risk for revision than were non-

Table 3. Distribution of recurrence of a herniated lumbar disc by BMI

\begin{tabular}{lccc}
\hline & \multicolumn{3}{c}{ BMI } \\
\cline { 2 - 4 } & $\begin{array}{c}\text { Normal } \\
(\mathrm{BMI}<\mathbf{2 5})\end{array}$ & $\begin{array}{c}\text { Overweight } \\
(\mathbf{2 5} \leq \mathrm{BMI}<30)\end{array}$ & $\begin{array}{c}\text { Obese } \\
(\mathrm{BMI} \geq \mathbf{3 0})\end{array}$ \\
\hline Non-recurred $(\mathrm{n}=136)$ & 23 & 52 & 61 \\
Recurred $(\mathrm{n}=24)$ & 3 & 8 & 13 \\
\hline
\end{tabular}

BMI : body mass index obese patients (OR, 1.20; 95\% CI, 1.06-1.37) (Table 3).

Table 4 shows the univariate and multivariate logistic regression analysis of revision surgery. Two variables remained statistically significant after adjusting for confounding factors : 1) Body mass index (OR, 1.30; 95\% CI, 1.12-1.52; $p=0.0007)$ and 2) Pfirrmann disc grade (OR, 2.13; 95\% CI, 1.29-2.97; $p=0.0002$ ).

Fig. 1 shows the Kaplan-Meier curves of the cumulative hazards of revision surgery stratified by BMI categories. Probability of revision surgery in obese group was significantly higher than normal and overweight group (log-rank test, $p<0.001)$. With increased BMI over 30, cumulative revision risk gradually increased.

\section{DISCUSSION}

The rate of HLD recurrence has not been well defined. The rates of HLD recurrence have a wide range because they can include disc herniations at the same level on the ipsilateral or contralateral side as the previous $\mathrm{LD}^{28,37,38)}$. However, our study only included patients with recurrent HLD at the same level and on the same side, which we considered to be more appro-

Table 4. Logistic regression analysis for revision surgery

\begin{tabular}{|c|c|c|c|c|}
\hline \multirow{2}{*}{ Variable } & \multicolumn{2}{|c|}{ Univariate } & \multicolumn{2}{|c|}{ Mulivariate } \\
\hline & OR $(95 \% \mathrm{Cl})$ & $p$-value & OR $(95 \% \mathrm{Cl})$ & $p$-value \\
\hline Sex & $0.55(0.10-3.03)$ & 0.4459 & & \\
\hline Age & $1.01(0.97-1.16)$ & 0.5103 & & \\
\hline Height & $0.95(0.86-1.04)$ & 0.2282 & & \\
\hline Weight & $1.07(0.95-1.19)$ & 0.2858 & & \\
\hline Body mass index & $1.77(1.13-2.41)$ & 0.0185 & $1.30(1.12-1.52)$ & 0.0007 \\
\hline Disc type & $0.83(0.76-0.91)$ & 0.9155 & & \\
\hline Pfirrmann disc grade & $3.14(2.67-3.61)$ & 0.0006 & $2.13(1.29-2.97)$ & 0.0002 \\
\hline Disc height & $0.87(0.38-1.99)$ & 0.5904 & & \\
\hline Body height & $1.07(0.96-1.18)$ & 0.7193 & & \\
\hline Disc/body height & $0.80(0.40-1.59)$ & 0.7458 & & \\
\hline Level of surgery & $1.24(0.58-2.65)$ & 0.4486 & & \\
\hline Type of surgery & $0.59(0.26-1.32)$ & 0.6762 & & \\
\hline Smoking & $1.12(0.92-1.33)$ & 0.5274 & & \\
\hline Hypertension & $1.80(0.57-3.69)$ & 0.3154 & & \\
\hline Diabetes mellitus & $1.28(0.30-2.23)$ & 0.7431 & & \\
\hline
\end{tabular}

OR : odds ratio, $\mathrm{Cl}$ : confidence interval 
priate. And Patients with recurrent symptoms, with radiographic evidence of reccurent HLD at the same side were considerd to recurrence group. The revision group was defined as the group of patients who had secondary LD for persistent symptoms after conservative treatment (Fig. 2).

Various studies have reported HLD recurrence after LD, and $5 \%$ to $15 \%$ of patients undergo secondary $\mathrm{LD}^{20,24)}$. Our study reported a $15 \%$ incidence of recurrence within a mean of 28.3 months. This study only includes patients with secondary LD. If we included patients who underwent spinal fusion due to back pain caused by instability, the recurrence rate would be much higher.
Proposed risk factors of HLD recurrence include age, sex, smoking, BMI, trauma, symptom duration, herniation type, level of the operation, degeneration, disc volume, and operative technique. Some researchers have found statistically significant differences based on age, sex, BMI, or degeneration. Our study found a statistically significant association with BMI and degeneration ${ }^{3,22,37)}$.

The intervertebral disc consists of an inner NP and an outer annulus fibrosus. The NP comprises mainly proteoglycans with type II collagen, and the annulus fibrosus comprises type I collagen. The proteoglycans, mostly aggrecans, bind with water to endure compressive loads and maintain tension on

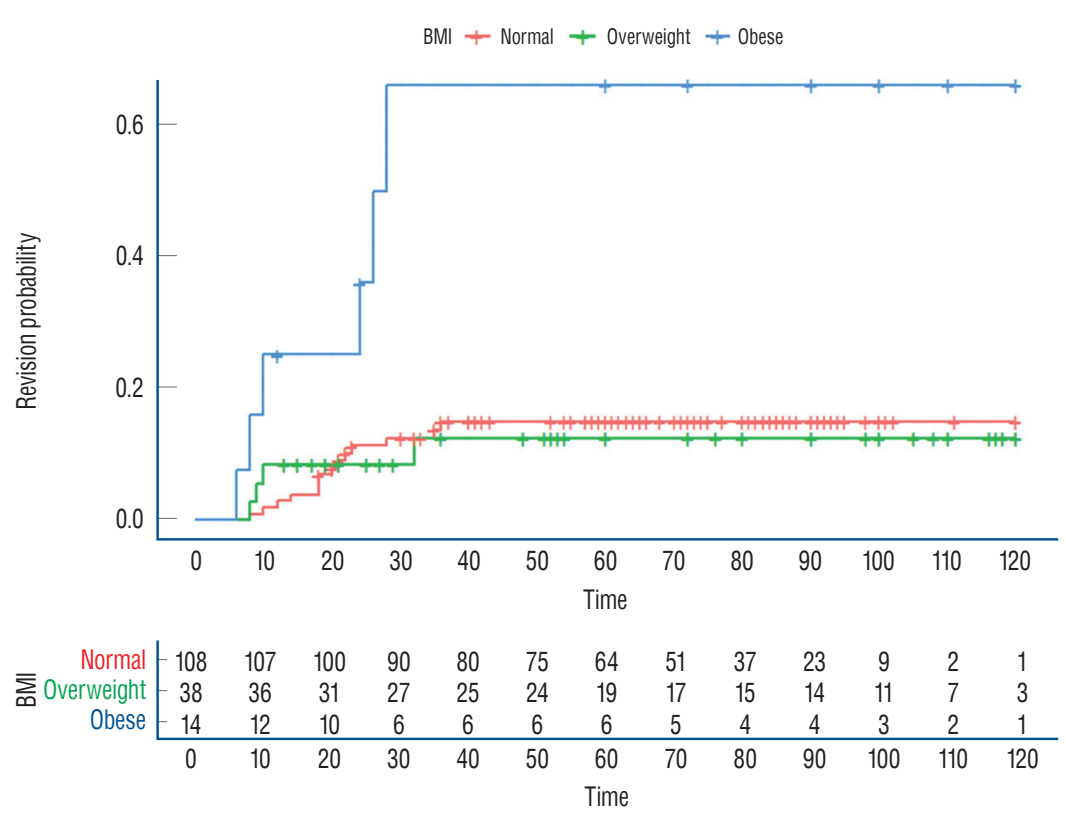

Fig. 1. Kaplan-Meier curves of cumulative hazards of revision surgery stratified by BMI categories (normal weight $<25.0$, overweight $25.0-30.0$, obesity $\left.\geq 30.0 \mathrm{~kg} / \mathrm{m}^{2}\right)$. log-rank test, $p<0.001$. BMI : body mass index.
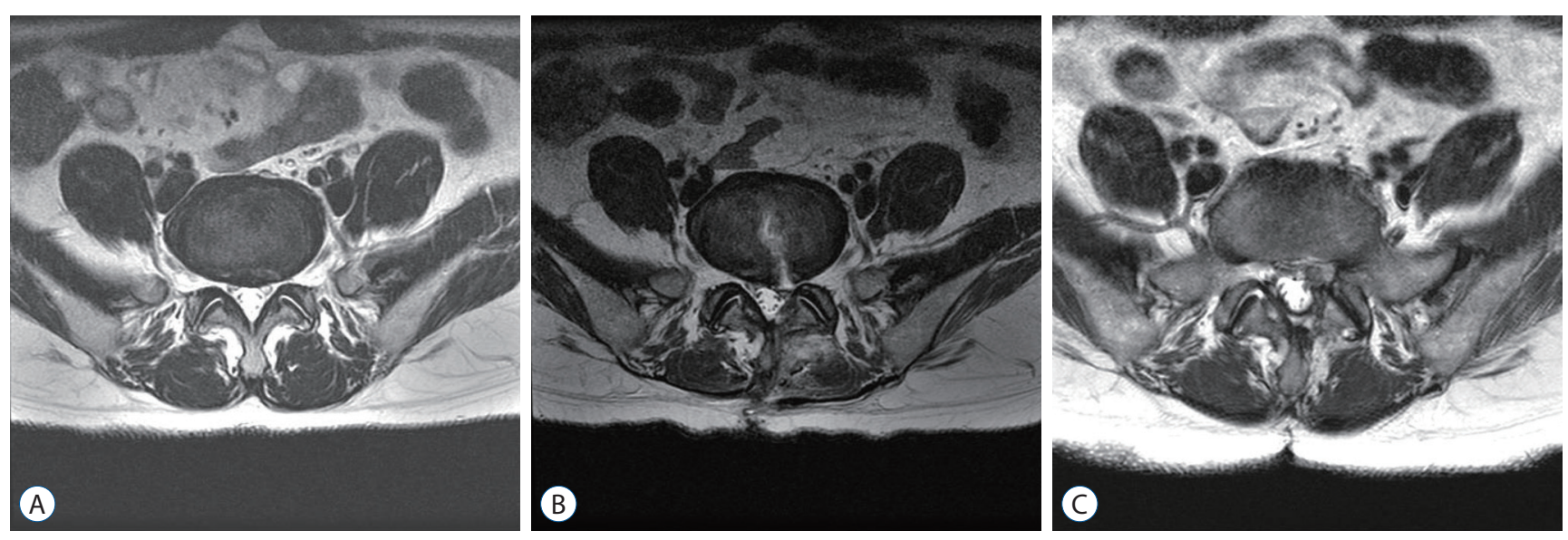

Fig. 2. A : MRI at the time of initial surgery decision. $B:$ MRI at the time of recurrence of symptoms. $C: M R I$ at the time of revision surgery decision. MRI : magnetic resonance image. 
the annulus fibrosus ${ }^{16,33)}$. When disc degeneration begins, cytokine levels increase and elevate aggrecans and matrix metalloproteinases. This process results in cleavage of NP substances and leads to loss of disc height ${ }^{1}$. Pfirrmann et al. ${ }^{32}$ studied this signal change on T2-weighted MRI, where a loss of brightness reflects proteoglycan degradation and water content ${ }^{10,12,33)}$.

We found a statistically significant association between disc degeneration assessed with the Pfirmann disc degeneration grade and HLD revision $(p<0.01)$. Cinotti et al. ${ }^{5}$ reported that, in severe degenerative disc patients, the annulus fibrosus showed a markedly low recovery rate after primary $\mathrm{LD}$, and the attenuated portion of the annulus fibrosus would aggravate recurrent HLD.

However, Dora et al. ${ }^{8}$ reviewed the relationship between disc degeneration assessed with five grading systems and HLD recurrence. They reported that patients with relatively lowgrade disc degeneration had a greater risk of recurrence. However, they included 60 non-randomized patients into each of the study and control groups. The correlation between age and Pfirrmann grade was found to be significant by Okada et al. ${ }^{25)}$. Dora et al. ${ }^{8)}$ did not consider older patients with a high Pfirrmann grade who underwent spinal fusion instead of LD due to spinal instability as a secondary operation. Therefore, a large randomized study with long-term follow-up should be considered $^{8}$.

High BMI is a well-known negative factor in spinal health and other general conditions $\mathrm{s}^{6,79,13,14,21,26-31,35,39)}$. Our study classified patients as normal (BMI under 25), overweight (BMI 25 to 30 ), or obese (BMI over 30). We compared obese and nonobese patients and found that obese patients were significantly more likely to have HLD revision $(p=0.0045)$. The idea that compressive loading on a intervertebral disc with a single or multiple stimuli after primary LD could result in HLD recurrence was suggested by Kelsey et al. ${ }^{18)}$ and Meredith et al. ${ }^{21)}$. In addition, biomechanical reviews have explained that repetitive increased tension on the annulus fibrosus greatly increases the risk of tearing in the posterolateral portion, leading to HLD. In obese patients, the axial load on the intervertebral disc is higher than in non-obese patients during weight bearing by the spinal column, consequently increasing HLD. Furthermore, a forward flexed position in obese patients could increase the HLD recurrence rate $e^{2,11,15,34,36,40)}$. Using BMI, which only considers height and weight, we might have misclassified patients who had high BMI due to high muscular mass as obese.

One limitation of our study is the small number of patients from a single medical center. Moreover, the retrospective medical information could introduce selection bias. Further study is required to assess the previously discussed factors in multiple hospitals over the long term. In this study, LD was the only reoperation considered. However, other procedure to assess spinal instability due to previous operations or aging should also be considered.

\section{CONCLUSION}

In our study, Pfirrmann disc degeneration grade and BMI were statistically significantly associated with HLD revision. After LD, surgeons should counsel patients with high BMI and degeneration on risk of revision.

The total numbers of patients and patients who underwent secondary LD were small, so further evaluation should be planned to confirm these results.

\section{CONFLICTS OF INTEREST}

No potential conflict of interest relevant to this article was reported.

\section{INFORMED CONSENT}

This type of study does not require informed consent.

\section{AUTHOR CONTRIBUTIONS}

\author{
Conceptualization : JYB, HJC \\ Data curation : JYB, HJC, KDK \\ Formal analysis : ISB \\ Methodology : JYB, HJC \\ Project administration : HJC, KHB \\ Visualization: JYB, KSC \\ Writing - original draft : JYB, HJC \\ Writing - review \& editing : JYB, HJC
}




\section{References}

1. Akyol S, Eraslan BS, Etyemez H, Tanriverdi T, Hanci M : Catabolic cytokine expressions in patients with degenerative disc disease. Turk Neurosurg $20:$ 492-499, 2010

2. Callaghan JP, Mcgill SM : Intervertebral disc herniation: studies on a porcine model exposed to highly repetitive flexion/extension motion with compressive force. Clin Biomech (Bristol, Avon) 16 : 28-37, 2001

3. Carragee EJ, Han MY, Suen PW, Kim D : Clinical outcomes after lumbar discectomy for sciatica: the effects of fragment type and anular competence. J Bone Joint Surg Am 85 : 102-108, 2003

4. Cheng J, Wang H, Zheng W, Li C, Wang J, Zhang Z, et al. : Reoperation after lumbar disc surgery in two hundred and seven patients. Int Orthop 37 : 1511-1517, 2013

5. Cinotti G, Roysan GS, Eisenstein SM, Postacchini F : Ipsilateral recurrent disc herniation. A prospective, controlled study. J Bone Joint Surg Br $80: 825-832,1998$

6. Cole JS 4th, Jackson TR : Minimally invasive lumbar discectomy in obese patients. Neurosurgery $61: 539-544,2007$

7. Djurasovic M, Bratcher KR, Glassman SD, Dimar JR, Carreon LY : The effect of obesity on clinical outcomes after lumbar fusion. Spine (Phila Pa 1976) 33 : 1789-1792, 2008

8. Dora C, Schmid MR, Elfering A, Zanetti M, Hodler J, Boos N : Lumbar disk herniation: do MR imaging findings predict recurrence after surgical diskectomy? Radiology 235 : 562-567, 2005

9. Dossett LA, Heffernan D, Lightfoot M, Collier B, Diaz JJ, Sawyer RG, et al. : Obesity and pulmonary complications in critically injured adults. Chest $134:$ 974-980, 2008

10. Emanuel KS, Vergroesen PP, Peeters M, Holewijn RM, Kingma I, Smit TH : Poroelastic behaviour of the degenerating human intervertebral disc: a ten-day study in a loaded disc culture system. Eur Cell Mater 29 : 330-340, 2015

11. Fabris de Souza SA, Faintuch J, Valezi AC, Sant'Anna AF, GamaRodrigues JJ, de Batista Fonseca IC, et al. : Postural changes in morbidly obese patients. Obes Surg 15 : 1013-1016, 2005

12. Farshad-Amacker NA, Farshad M, Winklehner $A$, Andreisek $G: M R$ imaging of degenerative disc disease. Eur J Radiol 84 : 1768-1776, 2015

13. Friedman ND, Sexton DJ, Connelly SM, Kaye KS : Risk factors for surgical site infection complicating laminectomy. Infect Control Hosp Epidemiol 28 : 1060-1065, 2007

14. Gepstein R, Shabat S, Arinzon ZH, Berner Y, Catz A, Folman Y : Does obesity affect the results of lumbar decompressive spinal surgery in the elderly? Clin Orthop Relat Res 426 : 138-144, 2004

15. Gilleard W, Smith $\mathrm{T}$ : Effect of obesity on posture and hip joint moments during a standing task, and trunk forward flexion motion. Int J Obes (Lond) 31 : 267-271, 2007

16. Griffith JF, Wang YX, Antonio GE, Choi KC, Yu A, Ahuja AT, et al. : Modified Pfirrmann grading system for lumbar intervertebral disc degeneration. Spine (Phila Pa 1976) 32 : E708-E712, 2007

17. Ito $T$, Takano $Y$, Yuasa $N$ : Types of lumbar herniated disc and clinical course. Spine (Phila Pa 1976) 26 : 648-651, 2001
18. Kelsey JL, Githens PB, O'Conner T, Weil U, Calogero JA, Holford TR, et al. : Acute prolapsed lumbar intervertebral disc. An epidemiologic study with special reference to driving automobiles and cigarette smoking. Spine (Phila Pa 1976) 9 : 608-613, 1984

19. Keskimäki I, Seitsalo S, Osterman H, Rissanen P : Reoperations after lumbar disc surgery: a population-based study of regional and interspecialty variations. Spine (Phila Pa 1976) 25 : 1500-1508, 2000

20. Kim MS, Park KW, Hwang C, Lee YK, Koo KH, Chang BS, et al. : Recurrence rate of lumbar disc herniation after open discectomy in active young men. Spine (Phila Pa 1976) 34 : 24-29, 2009

21. Meredith DS, Huang RC, Nguyen J, Lyman S : Obesity increases the risk of recurrent herniated nucleus pulposus after lumbar microdiscectomy. Spine J 10 : 575-580, 2010

22. Mobbs RJ, Newcombe RL, Chandran KN : Lumbar discectomy and the diabetic patient: incidence and outcome. J Clin Neurosci 8 : 10-13, 2001

23. Morgan-Hough CV, Jones PW, Eisenstein SM : Primary and revision lumbar discectomy. A 16-year review from one centre. J bone Joint Surg Br 85 : 871-874, 2003

24. Oh JT, Park KS, Jung SS, Chung SY, Kim SM, Park MS, et al. : Surgical results and risk factors for recurrence of lumbar disc herniation. Korean J Spine 9 : 170-175, 2012

25. Okada $E$, Matsumoto $M$, Fujiwara $H$, Toyama $Y$ : Disc degeneration of cervical spine on MRI in patients with lumbar disc herniation: comparison study with asymptomatic volunteers. Eur Spine J 20 : 585-591, 2011

26. Olsen MA, Lock-Buckley P, Hopkins D, Polish LB, Sundt TM, Fraser VJ : The risk factors for deep and superficial chest surgical-site infections after coronary artery bypass graft surgery are different. J Thorac Cardiovasc Surg 124 : 136-145, 2002

27. Olsen MA, Mayfield J, Lauryssen C, Polish LB, Jones M, Vest J, et al. : Risk factors for surgical site infection in spinal surgery. J Neurosurg 98 : 149-155, 2003

28. Olsen MA, Nepple JJ, Riew KD, Lenke LG, Bridwell KH, Mayfield J, et al. : Risk factors for surgical site infection following orthopaedic spinal operations. J Bone Joint Surg Am 90 : 62-69, 2008

29. Olsen MA, Sundt TM, Lawton JS, Damiano RJ Jr, Hopkins-Broyles D, Lock-Buckley P, et al. : Risk factors for leg harvest surgical site infections after coronary artery bypass graft surgery. J Thorac Cardiovasc Surg $126:$ 992-999, 2003

30. Park P, Upadhyaya C, Garton HJ, Foley KT : The impact of minimally invasive spine surgery on perioperative complications in overweight or obese patients. Neurosurgery 62 : 693-699, 2008

31. Patel N, Bagan B, Vadera S, Maltenfort MG, Deutsch H, Vaccaro AR, et al. : Obesity and spine surgery: relation to perioperative complications. J Neurosurg Spine 6 : 291-297, 2007

32. Pfirrmann CW, Metzdorf A, Zanetti M, Hodler J, Boos N : Magnetic resonance classification of lumbar intervertebral disc degeneration. Spine (Phila Pa 1976) 246: 1873-1878, 2001

33. Rim DC : Quantitative Pfirrmann disc degeneration grading system to overcome the limitation of Pfirrmann disc degeneration grade. Korean 
Risk Factors of Secondary Discectomy | Beack JY, et al.

J Spine $13: 1-8,2016$

34. Rodacki AL, Fowler NE, Provensi CL, Rodacki Cde L, Dezan VH : Body mass as a factor in stature change. Clin Biomech (Bristol, Avon) 20 : 799-805, 2005

35. Rosen DS, Ferguson SD, Ogden AT, Huo D, Fessler RG : Obesity and selfreported outcome after minimally invasive lumbar spinal fusion surgery. Neurosurgery $63: 956-960,2008$

36. Schmidt H, Kettler A, Heuer F, Simon U, Claes L, Wilke HJ : Intradiscal pressure, shear strain, and fiber strain in the intervertebral disc under combined loading. Spine (Phila Pa 1976) 32 : 748-755, 2007

37. Suk KS, Lee HM, Moon SH, Kim NH : Recurrent lumbar disc herniation: results of operative management. Spine (Phila Pa 1976) 26 : 672676, 2001

38. Swartz KR, Trost GR : Recurrent lumbar disc herniation. Neurosurg Focus $15: E 10,2003$

39. Tucker MC, Schwappach JR, Leighton RK, Coupe K, Ricci WM : Results of femoral intramedullary nailing in patients who are obese versus those who are not obese: a prospective multicenter comparison study. J Orthop Trauma $21:$ 523-529, 2007

40. Yar T : Spinal shrinkage as a measure of spinal loading in male Saudi university students and its relationship with body mass index. Saudi Med J 29 : 1453-1457, 2008 